\title{
A note on the larvicidal efficacy of saponin constituted crude extracts of plant and animal origin against Aedes aegypti $\mathrm{L}$.
}

\author{
S.N. Surendran ${ }^{\text {1* }}$, V. Kumaran ${ }^{1}$, R. Sivarajah ${ }^{2}$, S.R. Krishnarajah ${ }^{3}$, R. Srikaran ${ }^{2}$ and K. Raghavendra ${ }^{4}$ \\ ${ }^{\prime}$ Department of Zoology, Faculty of Science, University of Jaffna, Jaffna. \\ 2 Department of Chemistry, Faculty of Science, University of Jaffna, Jaffna. \\ ${ }^{3}$ Department of Zoology, Open University of Sri Lanka, Nawala, Nugegoda. \\ ${ }^{4}$ National Institute of Malaria Research, Indian Council of Medical Research, 22, Shamnath Marg, Delhi 110 054, India.
}

\begin{abstract}
Natural products of plant and animal origin are preferred over synthetic insecticides due to their eco-friendly nature. The use of natural products and their derivatives are being advocated for the control of insect vectors of human diseases. The crude extracts of the fruits of Sapindus emarginatus (a medicinal plant) and the skin of Holothuria atra (a nonedible sea cucumber) were tested under laboratory conditions against Aedes aegypti, a vector of dengue and chikungunya, for their larvicidal properties. Bioassay experiments carried out with crude extracts of $S$. emarginatus and $H$. atra revealed $\mathrm{LC}_{50}$ values of 92.9 and $68.82 \mathrm{ppm}$ respectively. Both crude extracts showed positive result for the presence of saponin. This preliminary study suggests that not only plant but also animal sources can be effectively used to produce less expensive and safe compounds to control mosquito vectors in Sri Lanka.
\end{abstract}

Keywords: Aedes aegypti, Holothuria atra, larvicide, Sapindus emarginatus, vector control.

\section{INTRODUCTION}

Mosquito-borne diseases such as malaria, dengue and chickungunya are of public health importance to Sri Lanka ${ }^{1-3}$. Even though there has been a drastic decline in reported malaria cases, severe epidemics of chickungunya and Dengue Fever (DF) / Dengue Hemorrhagic Fever (DHF) were reported from different parts of the country in recent times ${ }^{2-4}$. One option for management of insect vector-borne disease is to control the immature forms of vector mosquitoes. This method is more appropriate for the control of domestic and peri-domestic container breeding mosquitoes such as Aedes aegypti and A. albopictus, the vectors of dengue and chickungunya. At present, synthetic insecticides are heavily used for this purposes. The uses of chemical constituents of plant origin as a part of integrated vector control programme is encouraging due to their ecofriendly nature.

Natural products of plant origin have been tested for insecticidal properties to control disease vectors ${ }^{5-8}$, but extracts from animal origin have been rarely tested or reported. Sukumar et al. ${ }^{9}$ reported plants belonging to 99 families, 276 genera and 346 species to have insecticidal properties. Among the families reported 3 species of family Sapindaceae, namely Koelreuteria paniculata (extracts of seeds and leaves), Poullinia fuscescens (extracts of seeds and fruits) and Sapindus saponaria (extracts of seeds and fruits) were found to be effective against mosquito larvae. The present study was carried out in a laboratory to assess the larvicidal efficacy of the fruit extract of Sapindus emarginatus Vahl (Sapindaceae), a medicinal plant widely distributed in the dry-zone of Sri Lanka, against $A$. aegypti larvae. In addition, an attempt was made to identify crude extracts of animal sources with mosquito larvicidal properties. As sea cucumbers are reported to have medicinal values $^{10}$, extracts of dried skin of Holothuria atra Jaeger (Holothuroidea), a sea-cucumber widely present in the shallow waters of Sri Lanka with less consumer or economical demand were tested and the results are reported here.

\section{METHODS AND MATERIALS}

The fruits of S. emarginatus were collected in mid 2006 from Vavuniya (a locality in the northern dry zone of 
Sri Lanka) and H. atra was collected in early 2007 from the east coast of Jaffna peninsula of northern Sri Lanka. The collected $H$. atra was washed in running water and the skin was removed. The fruits of $S$. emarginatus and skin of $H$. atra were exposed to direct sunlight for 6-8 h a day for 14 days. The sun dried materials were chopped into small pieces with a knife and were powdered using a table model grinder. The powdered materials were stored in desiccators covered with aluminum foil. In the case of $H$. atra, initially $74 \mathrm{~g}$ of skin material was defatted using $250 \mathrm{~mL}$ dichloromethane at $40-45^{\circ} \mathrm{C}$ for $8 \mathrm{~h}$. Five grams each of the stored materials of $S$. emarginatus and $H$. atra were used for extraction. The crude extraction of $S$. emarginatus was carried out in a Soxhlet apparatus using $200 \mathrm{~mL}$ of absolute ethanol at $78^{\circ} \mathrm{C}$ for $8 \mathrm{~h}$. The residue fat-free $H$. atra was also extracted in Soxhlet apparatus in $250 \mathrm{~mL}$ of methanol at $60^{\circ} \mathrm{C}$ for $7 \mathrm{~h}$. The crude extracts were concentrated and solvents were removed under reduced pressure using a rotary vacuum evaporator. A portion of both crude extracts was tested for the presence of saponin using a standard method ${ }^{11}$. Stock solutions of desired concentrations $(0.45 \mathrm{~g} / 20 \mathrm{~mL})$ of $S$. emarginatus crude extract and $(1 \mathrm{~g} / 20 \mathrm{~mL})$ of $H$. atra were prepared using distilled water. Larval bioassays were carried out as per WHO techniques with slight modifications under laboratory conditions $\left(29 \pm 2^{\circ} \mathrm{C}\right)$. For each bioassay 15 healthy third instar larvae of laboratory reared A. aegypti were tested in plastic containers of 300 $\mathrm{mL}$ capacity containing $200 \mathrm{~mL}$ of dechlorinated water. In each case 5 different concentrations were prepared using the above stock solutions (ranging from 67.5 - 157.5 ppm for $S$. emarginatus and $62.5-175$ ppm for $H$. atra) and bioassayed using 3 replicates of each concentrations. Controls were run simultaneously with each set of experiments. Mortality of larvae was recorded after 24 h. The dose-mortality response values were analysed using log-probit regression analysis using the statistical software package 'Statistical Package for the Social Sciences' (SPSS; SPSS 12.0.1 for Windows, Chicago, Illinois, USA) to determine lethal concentrations for the mortalities of $50 \%$ and $90 \%$ of the treated larvae along with $95 \%$ Fiducial Limits.

\section{RESULTS AND DISCUSSION}

Bioassays with crude extract of $S$. emarginatus and $H$. atra against $A$. aegypti revealed the $\mathrm{LC}_{50}$ values of 92.9 and 68.82 ppm respectively (Table 1 ). Both extracts were positive for the presence of saponin.

$S$. emarginatus and $H$. atra could be used as sources to extract active compounds to produce effective mosquito larvicidal agents to control mosquito vectors. Preliminary studies are encouraging and studies on the larvicidal efficacy with other solvents and against other vectors are in progress.

\section{Acknowledgement}

Authors acknowledge the help rendered by A. Kajatheepan, K.A.F. Sanjeefkumar, P.J. Jude and S. Tharmasena of the Department of Zoology, University of Jaffna and the assistance of Dr (Mrs) P. Krishnarajah in the identification of specimens.

\section{References}

1. Public Health Services (2001). Annual Health Bulletin pp. 46-48. Public Health Services, Ministry of Health, Colombo 10.

2. Surendran S.N., Kannathasan S., Kajatheepan A. \& Jude P.J. (2007). Chikungunya-type fever outbreak: some aspects related to this new epidemic in Jaffna district, northern Sri Lanka. Tropical Medicine and Health 35(3): 249-252.

3. Surendran S.N., Kajatheepan A., Sanjeefkumar K.F.A. \& Jude P.A. (2007). Seasonality and insecticide susceptibility of dengue vectors: an ovitrap based survey in a residential area in northern Sri Lanka. Southeast Asian Journal of Tropical Medicine and Public Health 38(3): 276-282.

4. Kularatne S.A.M., Seneviratne S.L., Malavige G.N. \& Fernando S. (2006). Synopsis of findings from recent studies on dengue in Sri Lanka. Dengue Bulletin 30: 80-86.

Table 1: Laboratory evaluation of crude extracts of S. emarginatus and H. atra against third instar larvae of A. Aegypti

\begin{tabular}{lccccc}
\hline Source & Part of source & Solvent used & $\begin{array}{c}\mathrm{LC}_{50}(95 \% \mathrm{~F} . \mathrm{L})^{*} \\
\mathrm{ppm}\end{array}$ & $\begin{array}{c}\mathrm{LC}_{90}(95 \% \mathrm{~F} . \mathrm{L}) * \\
\mathrm{ppm}\end{array}$ & $\begin{array}{c}\chi^{2} \\
(\mathrm{df}=3)\end{array}$ \\
\hline S. emarginatus & fruit & ethanol & $\begin{array}{c}92.9 \\
(81.96-101.46)\end{array}$ & $\begin{array}{c}152.6 \\
(139.66-174)\end{array}$ & 2.654 \\
H. atra & & & 68.82 & 180.76 & \\
& skin & methanol & $(39.12-89.22)$ & $(154.53-227.25)$ & 3.266 \\
\hline
\end{tabular}

*Fiducial Limits 
5. Das N.G., Goswami D. \& Rabha B. (2007). Preliminary evaluation of mosquito larvicidal efficacy of plant extracts. Journal of Vector Borne Diseases 44(2): 145-148.

6. Choochote W., Tuetun B., Kanjanapothi D., Rattanachanpichai E. \& Chaithong U. (2004). Potential of crude seed extract of celery, Apium graveolens L., against the mosquito Aedes aegypti (L.) (Diptera: Culicidae). Journal of Vector Ecology 29(2): 340-346.

7. Singh R.K., Dhiman R.C. \& Mittal P.K. (2006). Mosquito larvicidal properties of Momordica charantia Linn (Family: Cucurbitaceae). Journal of Vector Borne Diseases 43(2): 88-91.
8. Mohammed A. \& Chadee D.D. (2007). An evaluation of some Trinidadian plant extracts against larvae of Aedes aegypti mosquitoes. Journal of the American Mosquito Control Association 23(2): 172-176.

9. Sukumar K., Michael J.P. \& Boobar L.R. (1991). Botanical derivatives in mosquito control: a review. Journal of American Mosquito Control Association 7(2): 210-237.

10. Kerr A.M. (2000). Holothuroidea. Sea Cucumbers. http://tolweb.org/Holothuroidea/19240/2000.12.01. Accessed in March 2008.

11. Kokate A. (1999). Phytochemical methods. Phytotherapy, $2^{\text {nd }}$ Edition. 78: 126-129. 